Instructions for authors, subscriptions and further details:

http://rasp.hipatiapress.com

\title{
Configuración de Subjetividades en la Contemporaneidad. Performance Escritural en Conversación con la Producción de la Artista Hispano-Mexicana Remedios Varo
}

Edilberto Hernández González

1) Facultad de Educación, Universidad Católica de Manizales. Colombia

Date of publication: February $3^{\text {rd }}, 2017$

Edition period: February 2017-June 2017

To cite this article: Hernández, E. (2017). Configuración de subjetividades en la contemporaneidad. Performance escritural en conversación con la producción de la artista Hispano-Mexicana Remedios Varo. Barcelona, Research, Art, Creation, 5(1), 76-91. doi: 10.17583/brac.2017.1836

To link this article: http://dx.doi.org/10.17583/brac.2017.1836

\section{PLEASE SCROLL DOWN FOR ARTICLE}

The terms and conditions of use are related to the Open Journal System and to Creative Commons Attribution License (CC-BY). 

pp. 76-91

\section{Setting the Contemporary Subjectivities. Performance in Writing about the Production of the Hispano-Mexican Artist Remedios Varo}

Edilberto Hernández

Faculty of Education, Catholic University of Manizales. Colombia

(Received: 4 December 2015; Accepted: 18 March 2016; Published: 3 February 2017)

\section{Abstract}

This reflective work is a scriptural performance around the production of the Hispano-Mexican artist Remedios Varo; approach which is based on a perspective of an aesthetic cognition. Mode relationship with knowledge that favors sensible possibilities of encounter with the world around us and who understands life as a constant movement of energy that is breath of beings and cosmic density. The meeting with Remedios Varo, as an artist who embodies a free spirit, was built in conversation with two experiences, one in Nobsa (Boyaca, Colombia) that has historically had a vocation craft production of textiles; and another made up of a stay in Mexico City. These experiences became key creative perception is subjective universe that Remedios Varo and his art. A work consisting of dynamic networks that interconnect with each other worlds. On the way of contemporary subjectivities, as the artworks of Remedios Varo are configured, spaces and bodies comprise complex, dramatic and emotional universes.

Keywords: contemporary subjectivities, subjectivized body, cognition aesthetics, Remedios Varo 

pp. 76-91

\section{Configuración de Subjetividades en la Contemporaneidad. Performance Escritural en Conversación con la Producción de la Artista Hispano-Mexicana Remedios Varo}

Edilberto Hernández

Facultad de Educación, Universidad Católica de Manizales. Colombia

(Recibido: 4 diciembre 2015; Aceptado: 18 marzo 2016; Publicado: 3 febrero 2017)

\section{Resumen}

Este trabajo reflexivo, constituye un performance escritural en torno a la producción de la artista Hispano-Mexicana Remedios Varo; aproximación que se sustenta en una perspectiva de cognición estética. Modo de relación con el conocimiento que privilegia posibilidades de encuentro sensible con el mundo que nos rodea y que comprende la vida como un movimiento constante de la energía que es aliento de los seres y densidad cósmica. El encuentro con Varo se ha construido en conversación con dos experiencias, una en Nobsa (Boyacá, Colombia); y otra, en Ciudad de México. Estas experiencias se convirtieron en claves creativas de percepción del universo subjetivo que constituye Varo y su obra artística, constituida por redes dinámicas que interconectan unos mundos con otros. El modo como se configuran las subjetividades contemporáneas, al igual que en la obra artística de Varo, los espacios y los cuerpos comprenden universos complejos, dramáticos y emocionales.

Palabras clave: subjetividades contemporáneas, cuerpos subjetivados, cognición estética, Remedios Varo

2017 Hipatia Press

ISSN: 2015-8992

DOI: $10.4471 /$ brac.2017.1836

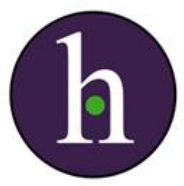




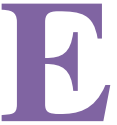

n la contemporaneidad se movilizan perspectivas filosóficas desde las cuales se conciben y promueven dinámicas de relación, cada vez más simétricas. Las relaciones intersubjetivas acontecen en medio de tramas contextuales, lo que hace que toda relación sea una posibilidad de configuración subjetiva. Aprendemos a vivir en medio de paisajes subjetivos. Pierre Hadot a propósito de su texto Elogio de Sócrates, propone una comprensión de las relaciones subjetivas centradas en la experiencia existencial del encuentro, al respecto dice:

El dialogo mismo, en cuanto acontecimiento, en cuanto actividad espiritual, ya ha sido una experiencia moral y existencial. Y es que la filosofía socrática no es una elaboración solitaria de un sistema, sino despertar de conciencia, acceso a un nivel de ser que no puede realizarse más que en una relación de persona a persona. (Hadot, 2006, p. 71)

También David Bohm plantea la posibilidad de una comprensión diferente del saber y sus posibilidades en la configuración de subjetividades. Para Bohm, el saber no es una realidad aislable y transmisible de unos a otros. El saber comprende una conciencia informada. Una conciencia que nos constituye y nos implica en el universo. Considera así mismo, que los sistemas de información organizados, principalmente las teorías son "una manera de formarse una idea, es decir, una manera de mirar el mundo, y no una forma de conocimiento de lo que es el mundo." (Bohm, 2008, p. 22)

La información acontece en un universo verdaderamente subjetivo. Universo donde se configuran las subjetividades. Movimiento cuidadoso, que no convoca acciones específicas. La información no refiere a un sólido. Refiere a un movimiento transformante; ella misma se transforma en la medida que constituye subjetividades. Un cuerpo es también un pensamiento. David Bohm lo expresa así: "la mente implica la materia en general y, por consiguiente, el cuerpo en particular. De un modo similar, el cuerpo implica no solo la mente, sino también, y en cierto sentido, el universo material entero." (Bohm, 2008, p. 289).

El lenguaje trasparenta la materia, trasparenta los cuerpos. Remedios Varo produce cuerpos trasparentes. Sus trazos tornan translúcidos los cuerpos humanos. Llevamos capas y capas de vestido para cubrir los 
abismos corporales. La transparencia es un acto que revela aquello que no está a la vista por estar demasiado cerca, eso que está allí y que requiere otros sentidos y también otros tiempos. Michel Serres lo dirá así: "Nuestro vestido cutáneo lleva y expone nuestros recuerdos, no los de la especie, como sucede con los tigres o los jaguares, sino los de la persona, a cada uno su propia mascara, su memoria exteriorizada." (Serres, 2002, p. 45).

Formarnos. Encontrar nuestra propia forma. Simular una forma. Formas subjetivas esculpidas en conversaciones con los otros. Nos formamos. Nos performamos a través de palabras, que son acciones, que son gestos, movimiento de los cuerpos. Las palabras son cinceles que tallan la subjetividad.

Grafías de la piel. El movimiento se hace cuerpo y el cuerpo se inventa gestos. Pulsión contenida, condensación del movimiento. Un cuerpo son sus gestos. La gestualidad corporal crea el espacio y el tiempo. Los gestos dibujan un mapa emocional en el espacio. Cartografías de los cuerpos que se aman. Cartografías del sufrimiento y el abandono. En las mañanas, los nevados como ancianos encorvados se asoman por las ventanas.

Los lenguajes artísticos configuran capas de esa conciencia informada y los caracteriza su inagotable pluralidad de voces. Jacques Rancière dirá que: "el espacio del arte se confirma como el espacio de la diversidad: diversidad de las competencias y de las funciones que borra los límites y mezcla las formas de experiencia y de expresión" (Rancière, 2005, p. 78), y hay artistas capaces de llevar el lenguaje artístico a confines de resonancia extraordinarios.

La producción de la artista Hispano-Mexicana Remedios Varo nos permite reflexionar en torno a la configuración de las subjetividades, reconociendo la manera como el medio que habitamos no solo deviene subjetividad, sino que él mismo se torna paisaje subjetivado. La acción de los lenguajes artísticos sobre el paisaje difiere de la subjetividad que imprimen en el paisaje urbano las pantallas publicitarias, interesadas exclusivamente en conducir y homogenizar el deseo subjetivo hacia el consumo. La obra de arte se presenta enigmática y convoca una experiencia sensible que resulta imposible de unificar.

La obra de arte crea lazo con el paisaje y los espacios se tornan subjetivos. Nuestra mirada y nuestras acciones sobre el espacio hacen que 
éste se transforme en un paisaje subjetivo. Un paisaje sensible y emocional. La obra de arte "performa" el espacio, dona su sensibilidad y el paisaje cobra otra forma.

Esta manera de comprender nuestros vínculos con la realidad implica una dinámica de sentido, de reconocimiento de la vida en general y de la existencia humana en particular. Movimiento, donde sensibilidad y espacio se presentan como dos instantes plegados de una misma realidad: la vida.

Remedios Varo, es una mujer de espíritu libre, que nutrió y dejó atravesar su vida y sus creaciones artísticas por los conceptos claves de la física cuántica y de una serie de pensamientos alternativos, como fue el surrealismo. Para Remedios Varo al igual que para Humberto Maturana

Lo humano no se constituye exclusivamente desde lo racional. Es cierto que lo racional es importante en el tipo de vida que vivimos, pero el primer paso para revalorar la emoción sería aceptar que entrelazado a un razonar está siempre presente un emocionar. (Maturana, 1992, p. 46)

Esta originalidad en su manera de posicionarse frente a la existencia, hacen de ella, una fuente inagotable de inspiración y búsqueda de sentidos. Tanto en Nobsa, como en Ciudad de México, son incontables las personas que me permitieron irrumpir en sus mundos y con sus palabras y con sus gestos generosos condujeron mi tránsito por las redes vitales y oníricas donde habita Remedios Varo, una vida que bordea todos los límites de lo socialmente esperado y una obra artística, constituida por imágenes de ensueño, pliegues escriturales y contextos diversos que conforman el cuerpo sensitivo que me permitió plasmar algunos trazos de la configuración de subjetividades en la contemporaneidad.

\section{Remedios Varo: Los Cuerpos y las Sustancias que los Habitan}

La vida y la obra de Remedios Varo nos orienta hacia un deseo de saber, de aprender y de crecer, por las vías de la incertidumbre; horizonte donde la apertura a los misterios de la existencia se constituyen en el camino por donde transita la experiencia de aprendizaje y convivencia, Denise Najmanovich (2011) considera que 
Pensar la subjetividad en el contexto social es entonces una tarea insumisa e irreverente: hace caso omiso de los cotos establecidos, corroe las certezas instaladas, exige una transformación de los saberes y las prácticas, indisciplina las problemáticas y crea nuevos ámbitos, teje conexiones inesperadas, recorre trayectos singulares y entraña un pensamiento ético-político sobre los saberes profesionales y sus destinos. (p. 97)

Remedios Varo envuelve los cuerpos, sus formas humanas son árboles cubiertos por ropajes verdosos cuyas puntas indican la dirección a otras realidades. A veces los cuerpos se tornan cautivos de sus propios envoltorios, como esos cipreses adolescentes que salpican las calles de Ciudad de México, los mismos que al atardecer se tornan fantasmas atrapados en sus divagaciones.

Cuerpos que simulan desplazarse protegidos, como quien teme a la intemperie. Son cuerpos que exhiben una gestualidad contenida, minimalista y carente de insinuaciones innecesarias; en ellos la propaganda exhibicionista está ausente. Tufic Makhluot me dice: ¡los personajes de Remedios tratan de moverse y no pueden! ${ }^{1}$ Esta idea es asombrosa pues, al pasearse por los cuadros de Remedios, se pudiera pensar que justamente dotar a los cuerpos de sofisticados aparatos de locomoción sería una manera de hacerlos más veloces. Entonces, estos cuerpos-máquinas son tal vez un desdén a tanto movimiento exterior. Una invitación a capturar el movimiento interno de las cosas, para lo que se requiere quietud y silencio.

Huimos siempre. La vida en todas sus dimensiones es transitoria, circula por sus propias densidades, a veces de una espesura a otra. Corrientes de agua abren surcos por territorios escarpados y contradictorios. "El agua lenta las variaciones mínimas lentas. El rostro leve lento. El suspiro cortado leve". ${ }^{2}$ La levedad de los cuerpos, también la levedad de nuestros cuerpos, facilita el tránsito hacia nuevos exilios. Remedios va de Anglés a Madrid. Enamorada y artista se traslada a París. Un retorno momentáneo a Barcelona. Otra vez París. París-ocupado, entonces Marsella, no! Es 1941, y los vientos húmedos de diciembre le dan la bienvenida a Ciudad de México. Remedios y su compañero aspiran con extrañeza y curiosidad los vapores del ponche ${ }^{3}$ que penetra todas las estancias de la vecindad. 
Cada viaje emprendido encarna una promesa pero, una vez se dan los primeros pasos, se nota cómo los cuerpos se deslizan por las estaciones, sus dramas forman espectros descoloridos, y se avanza con ellos a cada lado. Los espectros con frecuencia se cubren el rostro, temen algún flash extraviado que los devuelva al cuerpo donde un día residieron.

Transitar es abandonar. Una existencia ligera facilita el impulso para dar el siguiente paso. Hay cuerpos que a pesar de haber sido amados con la profundidad de la cual éramos capaces, terminan olvidados en alguna estación del metro, justo como se olvidan los nombres de las calles de ciudades recorridas sin ganas. Otros cuerpos se abandonan desgastados ya por el uso cotidiano. La sensibilidad necesaria para existir junto a otro cuerpo se desteje en el tedio de las tardes de verano; una que otra vez logramos renacer a la estación siguiente. Pero hay días en que no podemos más y nos marchamos definitivamente, con cierta prisa y con miedo a desfallecer, con miedo a quedarnos clavados en el sitio mientras un fuego devorador se propaga del tobillo al resto del cuerpo, convirtiéndonos en un montón de cenizas. ${ }^{4}$

Las mudanzas del universo nos sorprenden a la madrugada, cuando el existir confronta nuestros cuerpos. Rayos de sol asoman, rosas y tibios. Una vez más elegimos vivir. Remedios peregrina, tal vez solo transita a mundos imaginados. Europa se ha tornado pesada e insufrible y ella necesita un lugar para crear, para renacer e imaginar, quizás! En modos distintos, todos los universos son oníricos. Juliana González (2002), una destacada filosofa mexicana, describe así el universo de quien fuera una de sus grandes amigas:

...ahí donde ocurre lo imposible, donde los cuerpos adquieren diferente corporeidad, donde se producen las mezclas o combinaciones más insólitas e inconcebibles; donde el mundo conocido pierde su familiaridad, para dar lugar a algo que, sin embargo no es tan completamente otro como para que no nos diga nada, o que nos resulte absolutamente extraño e indiferente. (p. 89)

En su casa de la calle Álvaro Obregón, Remedios se despierta cada día sin otro ropaje más que la decisión de vivir. Sus creaciones se agitan contra los muros de la casa y germinan por cada agujero. Un amor de madurez 
produce olas repentinas que se revientan contra los acantilados; las burbujas y el olor del agua fresca se tornan universos coloridos.

Remedios habita tensiones que transfiguran lo cotidiano. Exiliada de sí, también lo está de las mezquindades de lo aparente. El prejuicio funda lo aparente. Huir es eso, quitar la primera piel a lo aparente, luego está la búsqueda interior que seduce y libera. Cuando transitamos mapas que desbordan el patio de nuestra casa, nos damos cuenta de lo inútil que resultan las marcas que imprimen las identidades. Remedios Varo es surrealista sólo en ese nivel que le permite crear su universo emocional, ella no está interesada en discursos que consuman su savia vital.

El cuerpo es la sustancia ${ }^{5}$, sin cuerpo solo hay vestido. El surrealismo perfora la unicidad de lo real y crea sus pluralidades. "Así como el caracolillo asoma sus antenas después de la lluvia y toma su baño, así el pececito, que no es otra cosa que nuestro corazón, ha volado.” (Perét, 1967, p. 64)

Ojos grandes y serenos rondan la obra creativa de Remedios Varo. Ojos que vieron la guerra desnuda, danzando el goce de sus miserias. Tus ojos, Remedios, han aumentado su superficie. Espejos de agua para conjurar el mundo. Lagunas sin fondo reflejan las fuerzas singulares que habitan los objetos. Espejos sucesivos nos devuelven retazos de existencias pasadas y venideras, tal vez! Subjetividades ligeras. Ojos enormes para ver los trasfondos del mundo y de los objetos, porque solo hay opacidades. La magia de la subjetividad recrea constantemente el mundo.

Un asfalto, fecundo y distante, impulsa la ebullición de una cosmogonía de la intimidad. Héroes destinados a transitar hacia mundos interiores. Existencias envolventes. Las ataduras de los objetos y los seres no responden a los movimientos torpes del azar. Remedios marca los vínculos, igual que las redes de las arañas entre las ramas de los árboles, sucesivas y fuertes.

Cosas que giran. Melódica locomoción de los cuerpos y las cosas. Los paisajes retornan serenos, las corrientes de asombro circulan por el interior de los cuerpos, de los objetos, del espacio y del tiempo mismo. Octavio Paz (1967, p. 51) dijo: "Remedios Varo: no pintó el tiempo sino los instantes en que el tiempo reposa". El reposo es también un estado de viaje, desenvolvimientos del existir, tránsito hacia capas más profundas, a esos rincones apartados donde habita cauteloso nuestro propio rostro. ${ }^{6}$ 
Remedios no miente, no ilusiona con las fantasías de lo irreal. Quizás el sentido de las grandes sagas de la existencia humana y también el de las fuerzas indomables que recorren en universo, no es otro que lograr apaciguar nuestros propios impulsos, a veces sombríos e inquietantes.

Una serpiente metálica recorre el submundo de Ciudad de México, se alimenta del calor y el aliento de los cuerpos humanos, los engulle a bocanadas y los regurgita hipóxicos en estaciones posteriores. En el Metro los cuerpos pierden toda su densidad, se repliegan sobre sí. Cuerpos que dormitan el cansancio del día y también el de los días venideros. La existencia cotidiana de los seres, testigos de las mezquindades que ha instaurado el capitalismo no esconde muchas sorpresas. Los cuerpos cotidianos en el Metro son, "piedras redondas como huevos petrificados." (Varo, 1994, p. 92)

Contradicción del existir, ¡El peso de sentir! ¡El peso de tener que sentir! (Pessoa, 1985, p. 233) Cotidianidad que atrapa y asfixia, también protege y conforta con la armonía de sonidos y los roces de los seres. Remedios, un existir en medio de contradicciones; ella lo supo, aun en medio de la placidez del existir, la incertidumbre hace su nido.

Una vida inocente, nada que temer, ni de dolor ni de culpabilidad, el metro cuadrado alrededor es completamente seguro, pero... tantas abejas han entrado y se han puesto a fabricar miel que ya casi un metro y me llega a más de medio cuerpo no sé qué hacer, si siguen quedaré enterrada en miel, adorable manera de morir. (Varo, 1994, p. 86)

Los cuerpos y los objetos se tornan volátiles. Física de lo volátil. Los cuerpos son el contenido y el soporte donde vamos constituyendo la obra fugaz que representa nuestro trascurrir por el mundo. Desenvolvimientos de la materia. Otros despertares. Cuerpos adormecidos, vaciados de sus propios deseos. El vacío es una manta que cubre las cosas y los cuerpos con su uniformidad, simetría de lo constante. Leyes de mercado cumpliendo juiciosamente su labor de producir subjetividades mercantiles. Deseo uniforme que no se interesa por el alma singular de los objetos. Estrategias del capitalismo cognitivo, puestas al descubierto por Suely Rolnik (2014), estrategias que extraen la energía de la invención, en aras de "la producción 
de sus cartografías prét-á-porter vacías y sin relieve, adaptables al consumo en cualquier punto del planeta." (p. 73).

\section{Cuerpos Tejidos con Hilos Quebradizos}

Remedios aprendió de niña a tejer abrigos para cubrir los cuerpos. Hilos protectores. En Nobsa hay una voz que dice: los mayores ya se han ido. Los cuerpos humanos apenas son hilos del bordado que constituye el manto terrestre ${ }^{7}$ Las fibras que le dan forma a los abrigos permanecen levemente atadas, solo entrelazadas, sus entrecruzamientos simulan las vidas humanas y facilitan los encuentros, las partidas y los reencuentros. Partir es siempre retornar a otros cuerpos, hasta que un día emprendes el viaje a estrellas lejanas, de donde un día habíamos salido con la promesa de volver.

Cada gesto es un hilo que atamos a otros tejidos. Tejemos la espera, rincones tenues donde a veces transcurre la cotidianidad. La esperanza se torna presente continuo, frío y nublado. Montañas descubiertas rodean Nobsa como animales envejecidos que han perdido el brillo de su pelaje. Maquinas ponzoñosas merodean por sus orillas, en una carrera infatigable por extraer de ellas hasta el último grano de roca caliza -remolino que a veces devora, alga que enreda, lo que quiere ascender hasta la superficie. Y no hay, entre el estruendo y su extinción, más que la turbiedad. ${ }^{8}$

Dolor reumático. ${ }^{9}$ El dolor es encadenarse a un deseo sin cuerpo, sin rostro aparente. Dolor de montañas hurgadas sin pudor. Indolencias que forjan modos de relación con el mundo. El dolor se maniobra con pinzas e hijos metálicos. Tramas tu red. Dueles tus ataduras, dueles el cuerpo y el universo. "Mira su cuerpo azul a punto de romperse. Mira que fácil su valor forma uno con la piedra. No habría ni que atarlo, no se iría." (Marrufo, 1987, p. 16) Para ciertos deseos no hay ungüentos posibles. Tampoco parece haber cura para la crueldad.

Tramar es entrecruzar hilos y destinos, como se entrecruzan los caminos veredales. Las pasiones humanas forman entrecruzamientos en diversas direcciones. Nobsa al igual que los cuerpos es lugar de intercambios de tejidos que vienen de diversas latitudes, como sentimientos, olores y miedos de la infancia. Imágenes de mundos habitados, resuenan confusas. Los miedos infantiles son como baúles donde se van guardando otros dolores y, 
cualquier día, apenas sin querer se abren. Martillo que toma su distancia para golpear con atrevimiento, hay veces que el estruendo se convierte en flor o en ave ligera.

El telar artesanal se alimenta de la energía del cuerpo, que es movimiento. El telar solo es máquina cuando el cuerpo se hace uno con él. El cuerpo crea el movimiento. Cada telar una historia, nombres, tiempo y movimiento, saber ancestral. Marcos abandonó el destino que el sistema había forjado para él, y vuelve al telar donde su padre, su abuelo y todos los anteriores han tejido el linaje familiar. Marcos tejerá sus días al ritmo lento del telar, fabricará tejidos, fabricará otras vidas. Objetos fibrosos saldrán de su taller dispuestos a abrigar otros cuerpos. Los tejidos recorrerán sus propios caminos y al igual que Remedios llegarán al amanecer a territorios distantes. Las fibras son seres con imaginación y buscan cuerpos que proteger.

Sentadas a la entrada de sus casas, mujeres tejen distraídamente sus atardeceres. Penélope envejecida, teje y espera, hay días en que parece esas montañas, lejanas y tristes. Sus manos tejen cada vez más lentamente, sus manos transmiten al tejido la languidez de su espera. Historias familiares, salpicadas de filamentos de tristeza, imperceptibles y fugaces. En Nobsa, los tejidos cuelgan de los techos que cubren los andenes por donde la gente pasa, allí donde acontecen los encuentros, allí donde uno que otro día, una mujer distraída olvidó descolgar un cuerpo. ${ }^{10}$ Remedios Varo en uno de sus relatos de sueños, narra el drama de una mujer que se percata de un olvido y pide a su verdugo diez minutos para enmendarlo, éste es el final del relato:

El material con el que lo tejí era como cintas que se materializaban en mis manos y que, sin ver de dónde venían, yo sabían que eran su sustancia y la mía. Cuando acabé de tejer esa especie de huevo, me sentí tranquila, pero seguía llorando. Entonces le dije al verdugo que ya podía matarme, porque el hombre que yo quería estaba tejido conmigo para toda la eternidad. (Varo, 1994, p. 67)

Rituales cotidianos para exorcizar el olvido. Ritual de malabares en Vía Corta. ${ }^{11}$ Juegos de realidades. Naturaleza que se hace persona, sensibilidades que embrujan a los objetos. Lo que somos es también otra realidad, otras existencias. Cuerpos transfigurados. Cuerpos en transformación, en retorno 
constante al cosmos a donde pertenecemos. Universos sonoros que evocan y propician encuentros.

\section{Los Cuerpos y sus Espacios}

Remedios crea universos emocionales. Mathias Goeritz, arquitecturas emocionales. Capas de espacio, capas de tiempo, capas de piel. Remedios y Mathias, han enmudecido a la narración cronológica de la existencia. Un lenguaje sensible cargado de emocionalidad irrumpe en sus cuerpos. Los cuadros de Remedios tienen una estructura de capas, comentó Enrique Mirabal.

Pista importante. Las creaciones de Remedios Varo las atraviesa un misterio que revela su vitalidad a través del encuentro amoroso con ellas. En uno de los soportes curatoriales de la exposición Arquitecturas del Delirio, Engel y Herranz (2009) se refieren al lenguaje arquitectónico recreado por Remedios Varo en sus obras como una arquitectura de estilización medieval que es escenario para los dramas que transcurren dentro, sin ser en realidad más que una sede atemporal para el sueño y el mito. Universos emocionales actúan a través de las energías que movilizan las interacciones. Inmersión en mares cálidos y profundos.

Experiencia de valor. Isaac encarna el valor mexicano, condición para acceder a las Torres de Satélites. ${ }^{12}$ Lo emocional es un sistema ilimitado de relaciones. Tejido que desborda la percepción racional del mundo. Regímenes sensibles configurándose a partir de la insinuación de elementos que convocan la multisensorialidad, como quien abre una puerta y se hace cuidadosamente a un lado, para que los cuerpos se sumerjan en un bosque de sensaciones. Juliana González (2002) describe con delicadeza los escenarios que Remedios Varo plasma en sus obras, dice que estos:

Suelen ser lugares solitarios, inmensamente solitarios, silenciosos y lejanos; sitios abandonados; ahí donde han penetrado las raíces y se han resquebrajado los muros. Ciudades dormidas o volcadas a su interior. Calles y escalinatas donde vuelan papeles. Bosques nocturnos, otoñales o invernales. Noches iluminadas; persistencia secreta y silente de la vida. Mares del "trasmundo." (p. 94) 
Torres emocionales, columnas desnudas, atléticas y libres de adornos innecesarios. Esculturas corporales, creaciones para ser vividas de cerca. Torres emocionales, cuerpos que invocan la ternura de la luz y de las sombras; el paso de las horas y las estaciones; la dirección de las corrientes de aire y la transformación de los materiales. Torres emocionales, cuerpos arquitectónicos en adoración al cosmos.

Lo emocional es más líquido que sólido, un tanto viscoso, quizás! Curvaturas del universo en busca de la oscuridad del deseo. Complejidad emocional que provoca la fascinación. Líneas proyectadas que al tocar los bordes de lo abrumador, se curvan para adherirse a la trayectoria de alguna estrella lejana y luminosa.

Arqueología de las emociones. Surcos de tiempo marcados en los cuerpos, en las esculturas de Mathias, en las pinturas y escritos de Remedios. Cuerpos ya sin piel se prolongan, sombras que quieren evitar lo inexorable. ${ }^{13}$ Paso del tiempo.

Sentimos que el tiempo ha transcurrido en la pintura de Remedios por la relación del personaje con el sillón y con todo el mobiliario. La mujer termina por confundirse con el mueble en el que de seguro ha permanecido sentada durante mucho tiempo: en el rostro se le ha impregnado el motivo de flores que el tapiz ostenta, y las manos y las piernas han adquirido respectivamente la forma de los brazos y las patas del sillón, mientras que los objetos han cobrado movimiento: buscan, roen, levitan, se entremezclan... ${ }^{14}$ (Celorio, 1974, p. 29)

Un eucaliptus ha sido plantado, Walter lo ha plantado para registrar el peso de la ausencia. Un eucaliptus arcoíris para que tengas a la mano todos los colores. Árbol viajero, que estará allí para cuando despiertes en las noches con sensación de soledad y te detengas a escuchar como el viento nocturno juguetea con las hojas y reproduce las apacibles cantatas de Telemann. ${ }^{15}$

La ausencia inaugura otras formas de estar juntos. Hay ausencias creativas. Instantes en los cuales nos vemos aguijoneados a inventar otras formas de presencia. Metáforas para producir nuevos universos sensibles. Tiempo. Energía. Espacio. Cuerpos. Subjetividades. Ficciones que narran la pluralidad de nuestras experiencias en el mundo. Experiencia, que es el mundo. 


\section{Notas}

${ }^{1}$ El encuentro con Tufic Makhluot y Enrique R. Mirabal sucedió el 9 de febrero de 2015. En un café de Insurgentes, a pocos metros del Parque Hundido en Ciudad de México.

2 César Moro (1980, p. 50). Poeta peruano, refugiado en México. Amigo cercano de Remedios Varo.

${ }^{3}$ Un amigo del D.F, me cuenta que el ponche se prepara así: agarras siete trozos de caña de azúcar, tres manzanas, tres guayabas, un tejocote, jamaica, tamarindo y ciruelas al gusto; lo dejas al fuego hasta que los frutos larguen su jugo y este adquiera el color y la textura de los muros de Luis Barragán. En este momento agregas cinco góticas de aceite de tlanapaquelite (preguntar en el mercado de Sonora), y un tris de picor. Esta receta es infalible para "alejar los sueños inoportunos, el insomnio y los desiertos de arenas movedizas bajo la cama”. (Varo, 1985, p. 15).

${ }^{4}$ La frase original de Remedios Varo en el proyecto para una obra teatral, dice: “...y la dejé clavada en el sitio mientras un fuego devorador se propaga del tobillo al resto del cuerpo, convirtiéndola en un montón de cenizas." (Varo, 1994, p. 92).

5 Alusión a la obra de Remedios Varo, Robo de sustancia, 1955, óleo sobre masonite.58x82cm. (Varo, 2002, p. 176). Respecto a la cita que le sigue, recordemos que Benjamín Perét es el poeta francés con quien Remedios Varo estuvo casada.

6 Alusión a la obra de remedios Varo, Encuentro, 1959, óleo sobre tela, 40x30cm. (Varo, 2002, p. 233).

7 Alusión a la obra de Remedios Varo, Bordando el manto terrestre, 1961, óleo sobre masonite. 100x123cm. (Varo, 2002, p. 254).

${ }^{8}$ Fragmento de un poema de Rosario Castellanos en honor de Remedios Varo, publicado por primera vez en la Revista de la Universidad de México el 26 de diciembre de 1963.

9 Alusión a la obra de Remedios Varo, Dolor Reumático I, 1948, gouache sobre cartulina, 25x19.2cm. (Varo, 2002, p. 157).

${ }^{10}$ Alusión a la obra de Remedios Varo, La tejedora roja, 1956, óleo sobre tela. $43.5 \times 28.5 \mathrm{~cm}$. (Varo, 2002, p. 186).

${ }^{11}$ Nombre de un Café en México D. F.

12 Mathias Goeritz, participó en el diseño y construcción de esta importante obra escultórica. Se encuentra ubicada en medio de dos avenidas de alta velocidad vehicular.

${ }^{13}$ Alusión a la Obra de Remedios Varo, La despedida, 1958, óleo sobre tela. 34x24cm. (Varo, 2002, p. 215).

${ }^{14}$ Los puntos suspensivos son del autor.

15 Walter Gruen, tenía entre sus favoritos a este compositor, devoción que se extendía a otros compositores alemanes entre ellos Bach y Beethoven, según me contó Ana Alexandra Varsoviano, en un encuentro que se realizó el 15 de febrero de 2015. Colonia Cuauhtémoc. 


\section{Referencias}

Bohm, David (2008). La totalidad y el orden implicado. Barcelona: Editorial Kairós, S.A.

Celorio, Gonzalo (1974). Remedios Varo y Remedios la bella. Un ejemplo indiscreto de arte comparado. Tesis de grado. México D.F.: UNAM, Facultad de Filosofía y Letras.

Engel, Peter \& Herranz, Iñaki (2009). Arquitecturas del Delirio. Plegable.

Disponible en http://static1.squarespace.com/static/53211690e4b03b 7284463ca8/t/5369586fe4b06d32ba4c3e8f/1399412847292/Remedi os+Varo\%2C+arquitecturas+del+delirio+2008.pdf Retomado: $26 / 02 / 2015$

González, Juliana (2002). "Mundo y trasmundo de Remedios Varo.” En:

Varo, Remedios. Catálogo Razonado. (3ª ed.). México D. F.:

Ediciones Era.

Hadot, Pierre (2006). Elogio de Sócrates. México D. F.: Solar, Servicios Editoriales.

Marrufo, Fernando (1987). El Libro de los Libros del Chilam Balam.

Yucatán, México: Ediciones de la Universidad Autónoma de Yucatán.

Maturana, Humberto (1992). El sentido de lo humano. (4 ${ }^{\mathrm{a}}$ ed.). Santiago de Chile: Ediciones pedagógicas chilenas, S.A.

Moro, César (1980). Obra Poética. Lima, Perú: Instituto Nacional de

Cultura. Dirección General de Difusión y Comunicación. Mérida, Yucatán, México.

Najmanovich, Denise (2011). El juego de los Vínculos. Subjetividad y redes: figuras en mutación. (2 ${ }^{\mathrm{a}}$ ed.). Buenos Aires: Editorial Biblios.

Paz, Octavio (1967). Apariciones y desapariciones de Remedios Varo. En:

Corriente Alterna. México D.F.: Siglo XXI, Editores S.A.

Perét, Benjamín (1967). Mueran los cabrones y los campos de honor. Traducción de Rodolfo Hinestroza. Barcelona: Tusquets Editor.

Pessoa, Fernando (1985). Libro del desasosiego. Traducción de Ángel Crespo. Barcelona: Seix Barral.

Rancière, Jacques (2005). Sobre políticas estéticas. Barcelona: Museu d'Art Contemporani de Barcelona. 
Rolnik, Suely (2014). Políticas de lo fluido, híbrido y flexible para evitar falsos problemas. En: Botey, Mariana \& Medina, Cuauhtémoc (Coord.). Estética y Emancipación: fantasma, fetiche, fantasmagoría. México D.F: Siglo XXI Editores

Serres, Michel (2002). Los cinco sentidos. Ciencia, poesía y filosofía del cuerpo. Bogotá: Taurus.

Varo, Remedios (1985). Consejos y Recetas. Pinturas, manuscritos y dibujos. Monclova, Coahuila, México: Museo Biblioteca Pape.

Varo, Remedios (1994). Cartas, Sueños y otros textos. Introducción y notas de Isabel Castell. (1 ${ }^{\mathrm{a}}$ ed.). México: Universidad Autónoma de Tlaxcala.

Varo, Remedios (2002). Catálogo Razonado. (3 ${ }^{\mathrm{a}}$ ed.). México D. F: Ediciones Era.

Edilberto Hernández González: Doctor en Educación. Profesor de la Maestría en Educación. Miembro del Grupo de Investigación ALFA.

Contact Address: Facultad de Educación, Universidad Católica de Manizales. Carrera 23, No. 60-30 Manizales.

E-mail address: ehernandez@ucm.edu.co edilbertohernandez09@gmail.com 